\title{
LARYNGOSCOPIC REMOVAL OF METALLIC FOREIGN BODY IN THE SUBGLOTTIC REGION OF LARYNX
}

Swastika Swaro ${ }^{1}$, Jaya Prakash Pani²

\section{HOW TO CITE THIS ARTICLE:}

Swastika Swaro, Jaya Prakash Pani. "Laryngoscopic Removal of Metallic Foreign Body in the Subglottic Region of Larynx". Journal of Evolution of Medical and Dental Sciences 2015; Vol. 4, Issue 17, February 26; Page: 30083011, DOI:10.14260/jemds/2015/436

ABSTRACT: Foreign body in respiratory tract is frequently encountered emergency in children. It is an important cause of morbidity and mortality among infants and small children. A 12 year old mentally retarded female child was brought to our hospital by anxious parents with history of swallowing a foreign body. Patient was having frequent cough and crying vigorously. On examination breathing was normal and vitals were stable. X-Ray neck showed an opened safety pin in sub-glottic region. The child was immediately taken for emergency bronchoscopic removal of foreign body under general anaesthesia. A laryngoscopic view revealed the metallic body just below the glottis hanging into the sub-glottic region. Immediately the foreign body was successfully removed with Magill's forceps.

KEYWORDS: Metallic foreign body, sub-glottic region, laryngoscope, Magill's forceps.

INTRODUCTION: Foreign body ingestion and impaction in the aero-digestive tract are common problem in children between 1-3 years age. ${ }^{1}$ Delay in removal of foreign body leads to increased mortality and morbidity. Most common foreign body in children are coin, bottom, pea nuts, seeds and less frequently metal and plastic particles. ${ }^{2}$ Diagnosis and required treatment depends on history, signs and symptoms, X-Ray neck and chest. A foreign body swallowed in esophagus presents with dysphagia and in respiratory tract presents with cough, dyspnoea and stridor. Sharing of airway by both anaesthesiologists and surgeons, poseses difficulty in ventilation. Associated edema and inflammatory changes may increase the risk of laryngospasm and bronchospasm. Here we are presenting the anaesthetic management of a metallic foreign body removal from sub-glottic of larynx in a mental retarded child with history of epilepsy and asthma.

CASE REPORT: A 12 years old female child was brought to our hospital with history of foreign body aspiration by parents. She was having cough. She was mentally retarded and was having history of epilepsy and asthma. On examination her vitals were stable and breathing normally. Chest X'Ray was normal. On X-Ray neck, an opened safety pin was found located in the sub-glottic region. Emergency Bronchoscopic removal of foreign body under general anaesthesia was planned. Preoperative assessment was done. Patient was shifted to OT. All routine monitors pulse-oxymetry, NIBP, ETCO2, ECG were attached. Emergency airway cart was kept ready if at all required (all types of LMA, ETT of smaller size, fiberoptic bronchoscope, $14 \mathrm{G}$ needle for needle cricothyroidectomy with percutaneous tracheostomy and surgical tracheostomy). 20G cannula was given and RL was started. Premedication was done with Glycoparolate (0.1 mg IV), Fentanyl (25 mcg IV), Midazolam (0.25 mg IV). She was induced with slow incremental doses of Propofol without muscle relaxant. Spontaneous mask ventilation maintained with 100\% 02. Inj. Deriphylline (1/2 amp IV), Inj. Dexamethasone (2 mg IV) was given. After induction a mild attack of seizure was observed. 


\section{CASE REPORT}

Immediately Midazolam (0.5mg) IV given. IV phenytoin sodium (20mg / kg)was given. Seizure was subsided within a minute. After adequate depth of anaesthesia, a direct laryngoscopy was done which revealed this foreign body in the sub-glottic region and it was removed with magill's forcep successfully. Recovery was uneventful. In the post-operative period, she was nebulized with Adrenaline (2 ML) and Combimist (to avoid any complication as she had history of asthma). The child was shifted to ward and subsequently dischargd.

Figure 1: (x-ray neck, lateral view) and Figure 2: (x-ray neck, AP view) shows an open safety pin in the subglottic region of larynx.

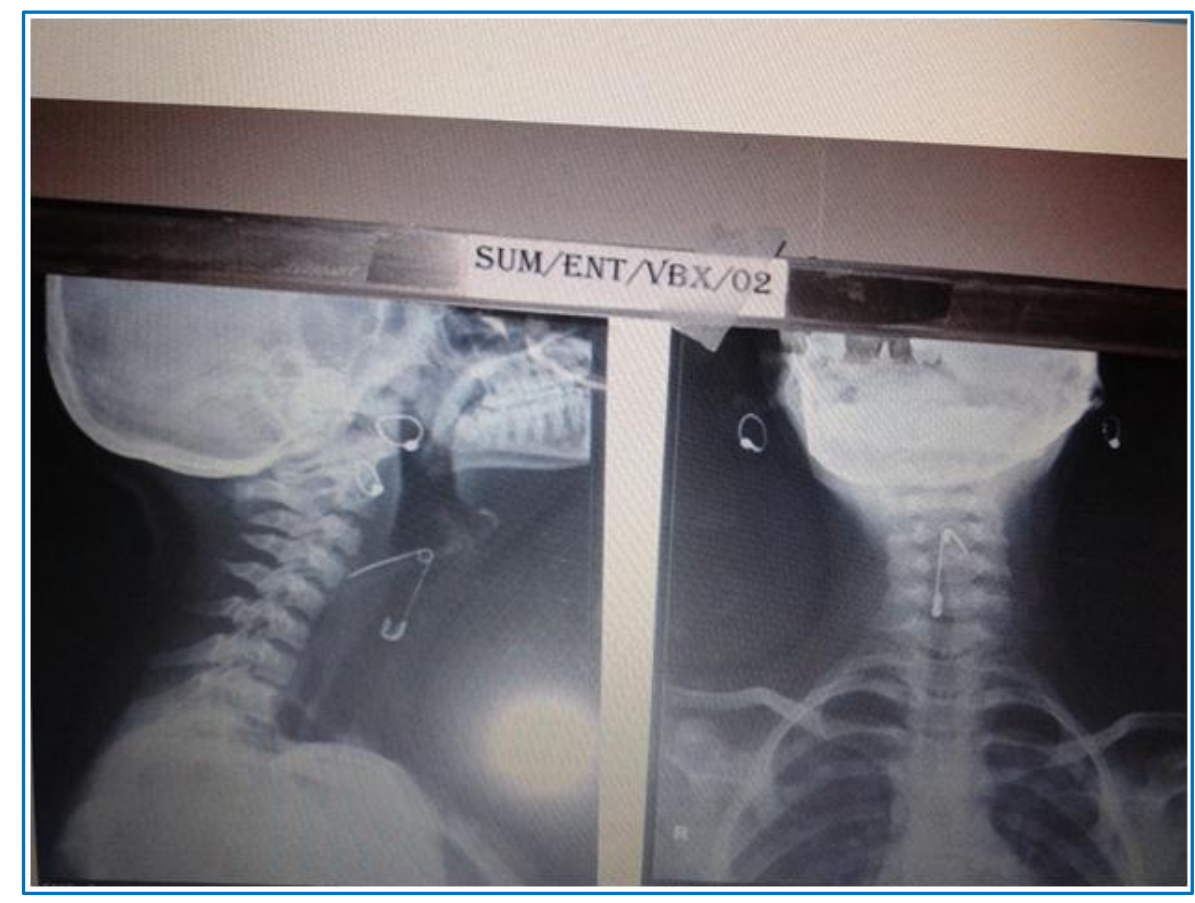

Fig. 1 \& Fig. 2

DISCUSSION: Foreign body ingestion is commonly encountered problem in emergency. The severity of symptoms depends on size, composition and duration of the foreign body. Clinical presentation varies widely which may be acute dysphagia, choking, drolling, dyspnoea, tachypnoea, striador, spasmodic cough or sudden death due to respiratory obstruction to accidental finding during routine investigation. In these cases, diagnosis may be difficult due to lack of clear history or clinical features or absence of X-Ray findings in case of radiolucent objects. Lannigan et al in 1987 have reported impaction of Lamb Bone in the subglottis of a smoker without any respiratory compromise. ${ }^{3}$ Keath et al also reported inhalation of a bottom at the carina in a post laryngectomy patient without any respiratory difficulty. ${ }^{4}$

General anaesthesia is usually preferred for endoscopic removal of foreign body in respitratory tract. ${ }^{5}$ Problem may be full stomach (In case of acute emergency) and sharing of airway by both surgeon and anaesthesiology makes ita challenge to maintain airway for adequate ventilation and oxygenation in children. During preoperative assessment the main focus should be on location of foreign body and degree of airway obstruction. 


\section{CASE REPORT}

The neck and chest roentgenograms are helpful in determining the location of the foreign body and pulmonary pathology. If a significant hyperinflation of one lung or lobe exists, nitrous oxide should be avoided to limit pulmonary inflation and potential rupture. ${ }^{6}$ Unless foreign body is visible in the airway; trachea should be intubated with 1 size smaller endotracheal tube without muscle relaxant.

As foreign body was in subglottic region just below the vocal cord as visualized by direct laryngoscopy, intubation could not be planned. PPV would have pushed the pin further down the trachea. So only, 14G needle cricothyroidectomy and if required precutaneous tracheostomy was plan B for airway management if required.

In this case she was induced with slow incremental doses of propofol to avoid apnoea with 100\%oxygen. Premedicated with glycopyrolate (To decrease secretion) and fentanyl (To obtained autonomic reflex of air-way instrumentation). Direct laryngoscopy was done and foreign body was visible which was removed by Magill's forceps.

If at all muscle relaxant required, we can use scolin to avoid excess neuromuscular blockade at the end of brief bronchoscopy. For removal of foreign body, rigid bronchoscopy is the equipment of choice. Unlike flexible bronchoscope, with rigid bronchoscope, the patient can be ventilated. Different ventilator techniques can be used during rigid bronchoscopy. In case of large laryngeal / tracheal foreign body, it can be removed with tracheostomy (Inhalation induction with Halothane / Succinylcholine is also a better choice).

CONSLUSION: Foreign body in respiratory tract is common in children and it's treatment is bronchoscopic removal under GA with a challenge for the anasthesiologists to maintain adequate oxygenation and preventing aspiration. So we should always be prepared with difficult airway cart.

\section{REFERENCES:}

1. Siddiqui MA, Banjar AH, Al-Najjar SM. Frequency of tracheobronchial foreignbody in children and adolescents. Saudi Med J 2000; 21: 368-71.

2. Mutogama EK, Davis PJ. Anaesthesia for ear, nose and throat surgery. Smith' sanaesthesia for infants and children. 6th ed., New York, Mosby year book, 1996. p. 669-74.

3. Lanningan EJ, New begin CJ. An unusual swallowed foreign body. J Laryngol Otol 1987; 101: 195-6.

4. Kieth AO. A tracheal foreign body. J. Laryngol Otol 1987; 101: 404-6.

5. Black RE, Johnson DG, Matlak ME. Broncoscopic removal of aspirated foreignbodies in children. J Pediatr Surg 1994; 29: 682-4.

6. Kalyanappgol VT, Kulkarni NH, Bidri LH. Management of tracheobronchialforeign body aspirations in paediatric age group: A 10 year retrospective analysis. Indian J Anaesth 2007; 51:20-3. 


\section{CASE REPORT}

\section{AUTHORS:}

1. Swastika Swaro

2. Jaya Prakash Pani

\section{PARTICULARS OF CONTRIBUTORS:}

1. Assistant Professor, Department of Anaesthesiology, IMS \& SUM Hospital.

2. Consultant, Department of Obstetrics \& Gynaecology, Apollo Hospital, Bhubaneswar.

FINANCIAL OR OTHER COMPETING INTERESTS: None

\section{NAME ADDRESS EMAIL ID OF THE} CORRESPONDING AUTHOR:

Dr. Swastika Swaro,

Department of Anesthesiology, IMS \& SUM Hospital,

Bhubaneswar.

E-mail: drswastika81@yahoo.com

Date of Submission: 03/02/2015. Date of Peer Review: 04/02/2015. Date of Acceptance: 18/02/2015. Date of Publishing: 26/02/2015. 